\title{
Grow Your Practice With Inbound Marketing Pauline Blachford
}

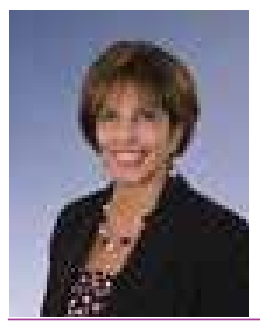

Pauline Blachford consults optometrists on how to reduce unbooked appointments, increase eyewear sales, and improve employee productivity. She has abundant experience in the eye health industry, including 17 years at White Rock Optometry in B.C. Pauline frequently presents at optometry conferences and is a regular columnist for the CJO. For more information, visit paulineblachford.com.

Tlove working with optometrists who are looking to grow their practice, particularly those

1 who are just starting out. I see their limitless potential, and they act like sponges, soaking up insights, new techniques, and my coaching.

When it comes to business development, these doctors are always excited to learn that their marketing strategy does not have to centre on costly and uninspiring newspaper ads. Those who work for more established optometrists also feel empowered when I remind them that they (not their bosses) are responsible for building their database of clients and filling their own schedules. For optometrists at this stage of their career, and indeed for all optometrists, the concept of "inbound marketing" can be pivotal.

\section{DEFINING INBOUND MARKETING}

Inbound marketing is about creating and sharing content that is valuable to your customers. This content attracts prospects to your business, where you can convert them into clients and delight them with your exceptional service. ${ }^{1}$ Mediums for inbound marketing include written articles or blogs, social media interactions, and oral presentations. Inbound marketing contrasts with outbound marketing, which aims to interrupt potential clients. Think TV commercials, newspaper ads, mass emails, and those weird Internet ads with flashing images of Dr. Oz. Outbound marketing tries to steal people's attention away from what they actually want to be doing, whether that's watching TV, catching up on the news, or checking emails.

The fundamental difference is that outbound marketing provides no value to the reader, viewer, or Internet browser-aside from informing them of the product or service being advertised. Inbound marketing has been on the rise since 2006, with some proclaiming the traditional outbound marketing playbook is broken. ${ }^{2}$ Figure 1 demonstrates that the vast majority of companies improve their marketing return on investment (ROI) after implementing inbound marketing. ${ }^{3}$

\section{INBOUND MARKETING FOR OPTOMETRISTS}

As optometrists, you are ideally suited to employ inbound marketing because you have rare knowledge that is valuable to your ideal clients. You spent eight years after high school studying to become a doctor of optometry. And you were not learning about nuclear physics or Roman history; you were studying something that affects all people, every moment of every day (I'm sure that nuclear physicists and Roman historians would say their disciplines also influence peoples' daily lives, but, come on!).

Inbound marketing is especially suited to doctors whose practices are still budding, since it requires time and effort to produce and distribute valuable content and does not require a substantial monetary investment. 


\section{INBOUND MARKETING ROI BY COMPANY TYPE}

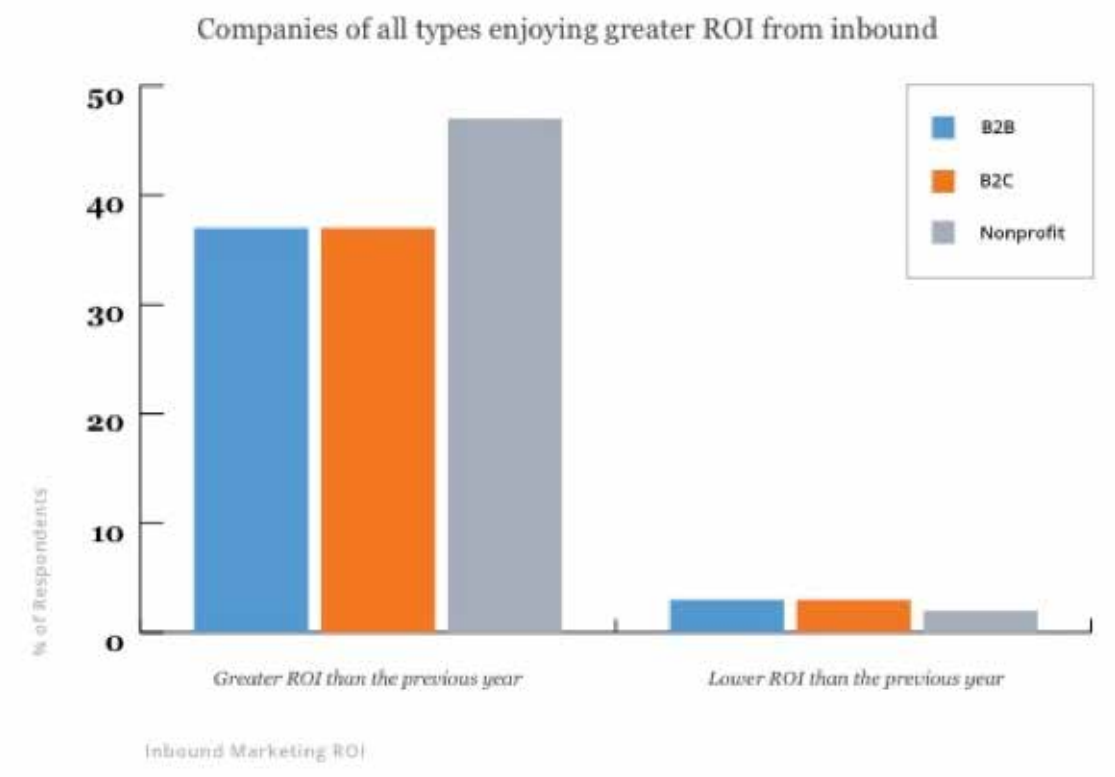

Figure 1. $B 2 B=$ business-to-business and represents companies that sell their products and services to other businesses. $\mathrm{B} 2 \mathrm{C}=$ business to consumers and represents companies that sell their products and services directly to consumers, such as optometry practices.

\section{INBOUND MARKETING IN ACTION}

To illustrate how the concept of inbound marketing can be applied, I obtained permission from a few of my excelling young clients to share their stories and successes. Dr. Heather Cowie owns her optometry practice with a fellow optometrist, Dr. Brent Hopfauf, in Airdrie, Alberta. Dr. Eva Kalicinsky owns and operates her own optometry practice in Cloverdale, BC. And Dr. Marina Ceaus practices optometry at a clinic owned by a well-established optometrist.

Dr. Heather has been doubling down on her inbound marketing since we began working together about seven months ago. After our first meeting, she contacted her local newspaper and now writes a monthly column called "Ask the Experts." She learned one of her patients was a teacher who asked her principal if Dr. Heather would speak to the parent committee on the importance of regular eye health exams for children. She also joined a Facebook group for mothers in her community. She scrolls the page and responds to questions that mothers post about their children's eye health and vision.

A creative inbound marketing medium that I heard of from Dr. Eva is called "Walk with the Doc." Local doctors in the area take turns going on walks with senior citizens, at which time the seniors can ask the doctors about the health issues they're facing. I love that even the format of the presentation (walking) promotes health and that the walk provides an open and accessible forum to connect with a population that needs special care.

By providing their communities with their valuable expertise, Drs. Heather and Eva are demonstrating they are caring and trustworthy. And trust leads to loyal clients. 
Dr. Marina recently made the shift from outbound to inbound marketing. She used to pay for an ad in a local newspaper, but wasn't satisfied with her ROI. She now puts her time and energy into keeping the practice's blog and social media current. This is wise, because studies have shown that websites with blogs receive $97 \%$ more indexed links, which causes them to rise to the top of the hits on Google. ${ }^{4}$

In the end, no two inbound marketing strategies are alike. The best inbound marketing strategies are highly individualized, leveraging the optometrist's unique personal characteristics and aptitudes. They also consider the demographics and needs of the community served by a practice. For help in developing an inbound marketing strategy that will help you grow your practice, contact me.

\section{REFERENCES}

1. Steenburgh T, Avery J, Dahod N. HubSpot: Inbound Marketing and Web 2.0. January, 2011. Harvard Business School. Available at: http://vsesdal.com/aukfiles/i4/ i440/cat44057/Case_HubSpot_gtsqyawmj78q.pdf. Accessed May 10, 2015.

2. Newlands M. The 8 fundamentals for a successful inbound marketing strategy. Available at:

http://www.entrepreneur.com/article/237040. Accessed May 10, 2015.
3. Bodi V. Need help to convince your team to adopt inbound marketing? Available at: www.business2community.com/inbound-marketing/ need-help-convince-team-adopt-inbound-marketing -01213101. Accessed May 10, 2015.

4. Lieberman, Mike. 10 stats about inbound marketing that will make your jaw drop. Available at: http://blog. hubspot.com/insiders/inbound-marketing-stats. Accessed May 10, 2015

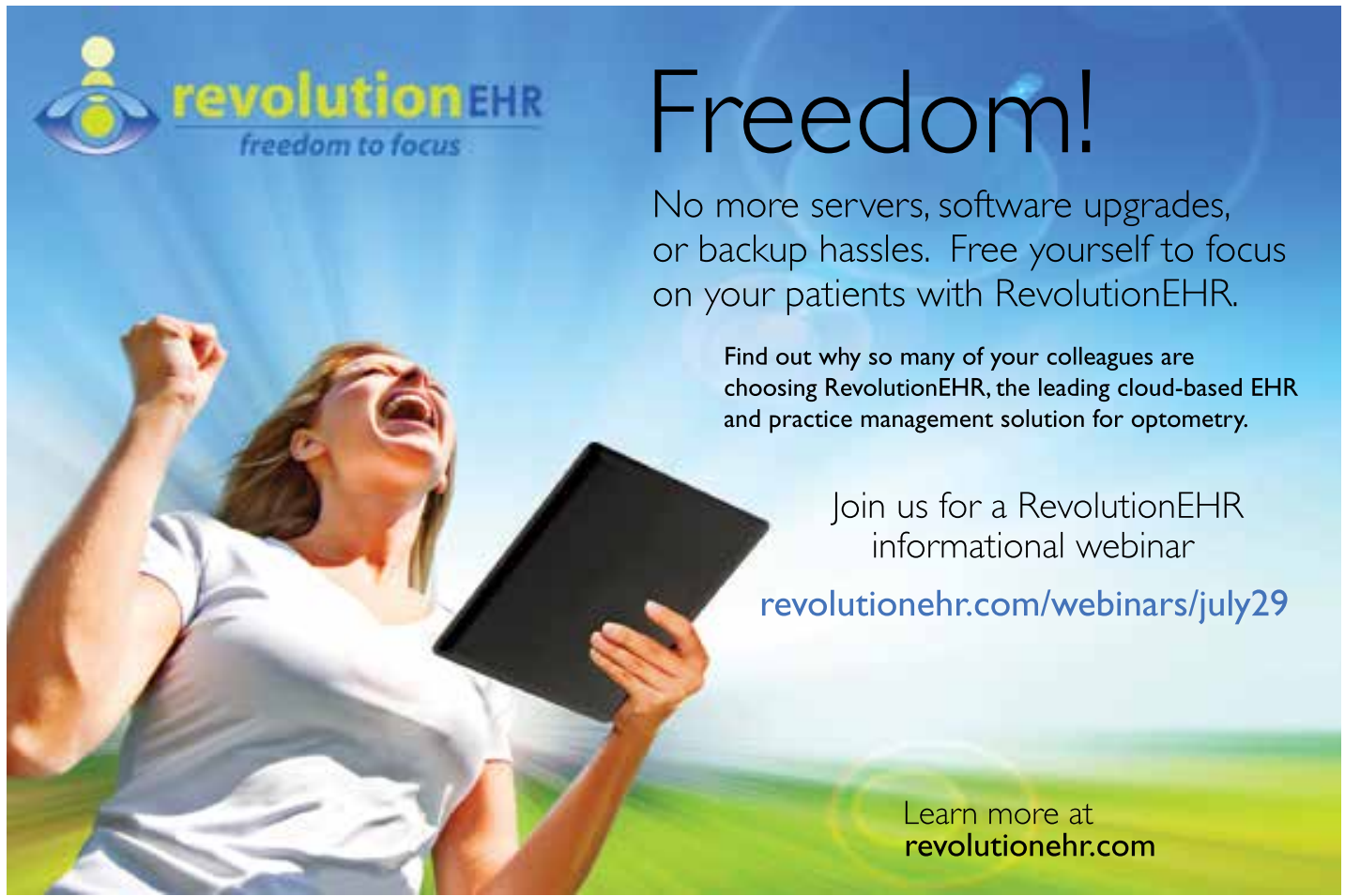

